\title{
Comparison of human erythrocyte purine nucleotide metabolism and blood purine and pyrimidine degradation product concentrations before and after acute exercise in trained and sedentary subjects
}

\author{
Wioleta Dudzinska $^{1}$ - M. Suska ${ }^{1}$ A. Lubkowska ${ }^{2}$ - K. Jakubowska ${ }^{3}$. \\ M. Olszewska ${ }^{3} \cdot$ K. Safranow ${ }^{3} \cdot$ D. Chlubek ${ }^{3}$
}

Received: 17 February 2016/Accepted: 25 March 2017/Published online: 21 April 2017

(c) The Author(s) 2017. This article is an open access publication

\begin{abstract}
This study aimed at evaluating the concentration of erythrocyte purine nucleotides (ATP, ADP, AMP, IMP) in trained and sedentary subjects before and after maximal physical exercise together with measuring the activity of purine metabolism enzymes as well as the concentration of purine (hypoxanthine, xanthine, uric acid) and pyrimidine (uridine) degradation products in blood. The study included 15 male elite rowers [mean age $24.3 \pm 2.56$ years; maximal oxygen uptake $\left(\mathrm{VO}_{2 \max }\right) 52.8 \pm 4.54 \mathrm{~mL} / \mathrm{kg} / \mathrm{min}$; endurance and strength training $8.2 \pm 0.33 \mathrm{~h}$ per week for $6.4 \pm 2.52$ years] and 15 sedentary control subjects (mean age $23.1 \pm 3.41$ years; $\mathrm{VO}_{2 \max } 43.2 \pm 5.20 \mathrm{~mL} / \mathrm{kg} / \mathrm{min}$ ). Progressive incremental exercise testing until refusal to continue exercising was conducted on a bicycle ergometer. The concentrations of ATP, ADP, AMP, IMP and the activities of adenine phosphoribosyltransferase (APRT), hypoxanthine-guanine phosphoribosyltransferase (HGPRT) and phosphoribosyl pyrophosphate synthetase (PRPP-S) were determined in erythrocytes. The concentrations of hypoxanthine, xanthine, uric acid and uridine were determined in the whole blood before exercise, after exercise, and $30 \mathrm{~min}$ after exercise testing. The study demonstrated a significantly higher concentration of ATP in the
\end{abstract}

Wioleta Dudzinska

wiola@univ.szczecin.pl

1 Department of Physiology, Faculty of Biology, University of Szczecin, 3c Felczaka St., 71-412 Szczecin, Poland

2 Department of Functional Diagnostics and Physical Medicine, Faculty of Health Sciences, Pomeranian Medical University in Szczecin, Szczecin, Poland

3 Department of Biochemistry and Medical Chemistry, Pomeranian Medical University in Szczecin, Szczecin, Poland erythrocytes of trained subjects which, in part, may be explained by higher metabolic activity on the purine resynthesis pathway (significantly higher PRPP-S, APRT and HGPRT activities). The ATP concentration, just as the ATP/ADP ratio, as well as an exercise-induced increase in this ratio, correlates with the $\mathrm{VO}_{2 \max }$ level in these subjects which allows them to be considered as the important factors characterising physical capacity and exercise tolerance. Maximal physical exercise in the group of trained subjects results not only in a lower post-exercise increase in the concentration of hypoxanthine, xanthine and uric acid but also in that of uridine. This indicates the possibility of performing high-intensity work with a lower loss of not only purine but also pyrimidine.

Keywords Exercise $\cdot$ Trained $\cdot$ Sedentary $\cdot$ Purine and pyrimidine nucleotides $\cdot$ Uridine $\cdot$ Erythrocyte $\cdot \mathrm{VO}_{2 \max }$. APRT · HGPRT

\section{Introduction}

In erythrocytes, the adenylate pool size (ATP + AD$\mathrm{P}+\mathrm{AMP}$ ) depends on the balance between AMP synthesis and degradation. AMP is related to the other pool components via the adenylate kinase reaction (2ADP $\leftrightarrow$ ATP + AMP) [1]. There are two pathways whereby AMP is synthesized in erythrocytes: from adenine and adenosine. The salvage of adenine depends upon two sequential enzymatic reactions. The first synthesizes 5-phosphoribosyl pyrophosphate (PRPP) from ribose-5phosphate and ATP in the presence of PRPP synthetase (PRPP-S; EC 2.7.6.1); in the second, adenine phosphoribosyltransferase (APRT; EC 2.4.2.7) catalyses the formation of AMP from PRPP and adenine [2]. On the other 
hand, adenosine kinase (EC 2.7.1.20) catalyses the salvage synthesis of AMP from adenosine and ATP. Besides adenine and adenosine, hypoxanthine (Hyp) is usually considered a major substrate of salvage pathways. Under normal conditions, up to $90 \%$ of Hyp, which is a breakdown product of ATP, is subject to reutilisation to IMP [3]. This reaction takes place in the presence of PRPP and is catalysed by hypoxanthine-guanine phosphoribosyltransferase (HGPRT; EC 2.4.2.8).

Physical exercise, particularly of high intensity, contributes to a decreased concentration of oxygen in relation to its demand, leading to bioenergetic hypoxia of muscles, the result of which is increased ATP degradation, being accompanied by IMP and $\mathrm{NH}_{3}$ accumulation $[4,5]$. Most IMP is re-synthesised to ATP during recovery in the purine nucleotide cycle, but part of IMP is dephosphorylated to a purine basis inosine (Ino), and then to Hyp [4]. The products of IMP degradation, particularly Hyp, may again be included in the IMP pool in the reaction being catalysed by HGPRT (purine salvage pathway) or, after leaving the muscle, may accumulate in blood plasma [6-9]. Owing to membrane transporters, nucleosides and purine bases (mainly Hyp) are in the balance between blood plasma and erythrocytes, for which they constitute a substrate in salvage-type reactions [2].

In addition, one of the permanent phenomena accompanying intense physical exercises is metabolic acidosis and hyperphosphatemia. The higher an increase in the hydrogen ion concentration, the higher the exercise intensity. A fall in $\mathrm{pH}$ in red blood cells results in a decrease in 2,3-BPG and ADP (allosteric inhibitors of PRPP-S) with a concomitant increase in intracellular inorganic phosphate-Pi (PRPP-S activator) and ATP [10]. Thus, an increase in $\mathrm{Pi}$ concentration in blood together with a decrease in $\mathrm{pH}$ could play a supportive role in the activation of PRPP-S because this enzyme has an absolute requirement for $\mathrm{Pi}$ for its activation $[10,11]$. Therefore, exercise could favour increased synthesis of PRPP, a cosubstrate in the reactions being catalysed by APRT and HGPRT and, in consequence, result in an increase in the metabolic activity of purines on the salvage pathway. There is some support in the literature for the hypothesis being made. An in vitro study on the effect of $\mathrm{Pi}$ on purine nucleotide concentration showed that an increase occurred in IMP concentration in red blood cells being incubated in a solution containing $2 \mathrm{mmol} / \mathrm{L} \mathrm{Pi}$ (more than the physiological concentration) $[10,12]$; the in vitro study demonstrated that the uptake of Hyp and accumulation of IMP in red blood cells is significantly intensified at acidic $\mathrm{pH}$, high external phosphate concentrations, and low $\mathrm{pO}_{2}$, i.e. under the conditions which accompany intense physical exercise. They suggested that erythrocytes could play a role in the removal of Hyp from anoxic tissue. In addition, the enhanced synthesis of PRPP explains the increased levels of ATP and IMP found in the erythrocytes of patients with chronic renal failure, in which blood $\mathrm{pH}$ is decreased and plasma Pi concentrations are increased [13-15].

Thus, a post-exercise increase in the concentration of purine re-synthesis substrates (mainly Hyp), and an increase in the concentration of plasma phosphate, especially in combination with acidosis, may lead to changes in the activity of enzymes being involved in purine metabolism and, in consequence, in their concentrations. Therefore, there are reasons to evaluate the effect of high-intensity physical exercise on the concentration of purine nucleotides in red blood cells. This is increasingly true in that there are limited data so far on the post-exercise changes in erythrocyte purine concentration; they are not very consistent and refer mainly to evaluation of the effect of physical exercise on the concentration of adenine nucleotides in the red blood cells of untrained subjects. In these studies, some authors report an increase in ATP concentration [16], whereas other ones show no changes in ATP concentration [17, 18]. Those differences are probably due to different protocols, i.e. different characteristics of subjects (age, physical activity, health), different training and tests (type, intensity, duration of exercise tests), various methods of measuring the purine concentration, etc. The absence of studies investigating the effect of physical exercise on purine metabolism in the erythrocytes of trained subjects is surprising, in view of the fact that training leads to many adaptive changes, also in blood and the erythrocyte system [19]. Training enhances $\mathrm{O}_{2}$ flux to the working muscles at all levels of regulation: it increases maximal cardiac output, improves blood flow to the muscles by stimulating vascularisation, and improves the rheological properties of red blood cells. Training increases total haemoglobin mass which increases the amount of $\mathrm{O}_{2}$ that can be carried by blood. It also increases red blood cell 2,3-BPG, which increases the sensitivity of $\mathrm{Hb}-\mathrm{O}_{2}$ affinity to acidification-dependent $\mathrm{O}_{2}$ release [19]. It was also shown that adaptation to physical exercise in trained subjects is associated with the improvement of potential for re-phosphorylation of Hyp to IMP through increased HGPRT activity in the muscles [20].

Given the above, this study involved evaluation of the concentration of purine nucleotides (ATP, ADP, AMP, IMP) in the erythrocytes of trained and sedentary subjects before and after maximal physical exercise together with measuring the activity of purine metabolism enzymes being under the regulatory effect of $\mathrm{pH}$ and Pi. Furthermore, apart from evaluation of resting and post-exercise changes in the concentration of purine degradation products in blood, i.e. Hyp, xanthine (Xa) and uric acid (UA), changes in the concentration of uridine (Urd), which is a product of pyrimidine degradation, was measured. To our knowledge, this is the first study in this area. 
One of the main effects of regular physical activity is increased physical capacity, a measure of which is the magnitude of maximal oxygen uptake $\left(\mathrm{VO}_{2 \max }\right)$. It is now accepted that the $\mathrm{VO}_{2 \max }$ during whole-body exercise in humans is not constrained by the capacity of mitochondrial oxygen consumption but by the magnitude of oxygen delivery to the working muscles $[21,22]$. A recent study has shown that erythrocyte ATP concentration and changes in its level may regulate the magnitude of oxygen delivery to tissues [23]. Therefore, the study evaluated a relationship between the $\mathrm{VO}_{2 \max }$ level and the ATP concentration.

\section{Materials and methods}

\section{Subjects}

The study included 15 male elite rowers (mean age $24.3 \pm 2.56$ years, endurance and strength training $8.2 \pm 0.33 \mathrm{~h}$ per week for $6.4 \pm 2.52$ years) and 15 sedentary control subjects (mean age $23.1 \pm 3.41$ years).

A typical training program for the rowers comprised rowing at different energy expenditure levels in addition to one or two weight-lifting sessions. In the group of rowers, examinations were conducted at the end of the preparatory period.

The control subjects performed normal daily activities and had never participated in regular endurance training; for at least the previous 2 years, they had not been involved in any competitive or recreational sports.

All subjects were healthy and normotensive, with a body mass index (BMI) between $21.5 \pm 2.51 \mathrm{~kg} / \mathrm{m}^{2}$ (trained) and $22.5 \pm 2.32 \mathrm{~kg} / \mathrm{m}^{2}$ (sedentary). Anthropometric and physiological characteristics of the participants are presented in Table 1. They had no history of any metabolic and cardiovascular diseases. The participants were nonsmokers and refrained from taking any medications or supplements known to affect metabolism.

Participants were volunteers and were informed about the study protocol, the risks of all tests, their rights, and they gave their written informed consent before the initiation of the experiment. The study was approved by the local ethics committee (Ethics Committee of Pomeranian Medical University) in accordance with the Helsinki Declaration.

Exercise testing was performed at the laboratory of the Department of Physiology, Faculty of Biology, University of Szczecin, Poland, in the early-morning hours. The subjects reported to the laboratory a few hours after having a light breakfast (without tea and coffee).

\section{Anthropometric measurements}

Body height $(\mathrm{cm})$ was measured to the nearest centimeter using a rigid stadiometer. Body mass $(\mathrm{kg})$ was measured in
Table 1 Baseline characteristics of sedentary and trained subjects

\begin{tabular}{lll}
\hline & Sedentary group & Trained group \\
\hline Number & 15 & 15 \\
Age (years) & $23.1 \pm 3.41$ & $24.3 \pm 2.56$ \\
BMI $\left(\mathrm{kg} / \mathrm{m}^{2}\right)$ & $22.5 \pm 2.32$ & $21.5 \pm 2.51$ \\
HRrest $(\mathrm{bpm})$ & $63.1 \pm 7.51$ & $59.0 \pm 6.33$ \\
SBP $(\mathrm{mmHg})$ & $113.4 \pm 9.24$ & $117.6 \pm 8.32$ \\
DBP $(\mathrm{mmHg})$ & $72.5 \pm 6.11$ & $68.2 \pm 7.21$ \\
Duration of training (years) & - & $6.4 \pm 2.52$ \\
Training time (hours per week) & - & $8.2 \pm 0.33$ \\
Time of exercise test (min) & $19.3 \pm 4.55$ & $23.0 \pm 5.97$ \\
VO & \\
2,3-BPG $(\mathrm{mL} / \mathrm{kg} / \mathrm{min})$ & $43.0 \pm 5.20$ & $52.8 \pm 4.54^{* *}$ \\
\hline
\end{tabular}

Values are given as mean $\pm \mathrm{SD}$

$B M I$ body mass index, $H R$ heart rate, $S B P$ systolic blood pressure, $D B P$ diastolic blood pressure, $V O_{2 \max }$ maximal oxygen uptake, 2,3$B P G$ 2,3-bisphosphoglycerate

$* P<0.01 ; * * P<0.001$; different from sedentary

underwear to the nearest $0.1 \mathrm{~kg}$ using an electronic scale. BMI was calculated by dividing weight in kilograms by height in square meters $\left(\mathrm{kg} / \mathrm{m}^{2}\right)$.

\section{Blood pressure}

Systolic and diastolic blood pressure (SBP and DBP) were measured according to guidelines at the right arm after a 10 -min rest by using a calibrated sphygmomanometer.

\section{Experimental protocol}

The participants were subjected to tests of maximal physical capacity, establishing their maximal oxygen uptake $\left(\mathrm{VO}_{2}\right.$ max) using a direct method. In order to estimate $\mathrm{VO}_{2 \max }$, a progressive ergocycle test was applied. The exercise was preceded by a 5-min warm-up $(25 \mathrm{~W})$. The test was performed on a bicycle ergometer (Kettler X-7, Germany).

The proper test began at $70 \mathrm{~W}$ while maintaining 70 revolutions per minute. The effort continued with an increasing load (20 W every $3 \mathrm{~min}$ ) until refusal, or until a tested individual was not able to maintain the required rotation frequency [24].

During the exercise, oxygen uptake $\left(\mathrm{VO}_{2}\right)$ was measured continuously using an Oxycon gas analyzer (Jaeger, Germany). Heart rate was measured with a Polar sport tester.

\section{Sample collection}

Venous blood was taken from the antecubital forearm vein before exercise, after exercise, and $30 \mathrm{~min}$ after exercise 
testing. Blood samples were taken into two separate tubes (Monovette ${ }^{\circledR}$, Sarstedt, Germany). The first tube consisted of lithium heparinate $(15 \mathrm{IU} / \mathrm{mL}$ blood, $4.9 \mathrm{~mL})$ and the second one (which was used for detrermination of purines and pyrimidines) of sodium fluoride and lithium heparin $(1 \mathrm{mg} / \mathrm{mL}$ blood $+16 \mathrm{IU} / \mathrm{mL}, 2.7 \mathrm{~mL})$.

Both concentration of tested compounds and activity of enzimes were determined in whole blood, red blood cells and plasma. Thus, later procedures were carried out according to specific methods of determination. They are presented in the section below.

\section{Blood analysis}

Venous blood gases were determined by using a blood gaspH analyzer (Ciba Corning 248 blood gas-pH analyzer, Medford, MA, USA).

Inorganic phosphorous in plasma was determined using a Randox Laboratory diagnostic kit REF PH1016 (Randox Laboratories Ltd. Co. Antrim, UK).

Lactate concentration was determined using a Dr Lange Lp-20 analytical kit (Lange, Germany).

To measure 2,3-BPG concentration in red blood cells, the ultraviolet enzymatic method (Kit 35-UV, Sigma, St. Louis, MO, USA) was used.

\section{Determination of purines and pyrimidines}

The purine nucleotide (ATP, ADP, AMP, IMP) concentrations were determined in erythrocytes. The Hyp, Xan, UA and Urd concentrations were determined in the whole blood. The purine and pyrimidine concentrations being analysed were determined by high-performance liquid chromatography (HPLC) according to the method used by Smolenski et al. [25].

In order to isolate erythrocytes, blood samples were centrifuged within $5 \mathrm{~min}$ from taking a sample $(650 \times g$, $10 \mathrm{~min}, 4^{\circ} \mathrm{C}$ ). The plasma and buffy coat were removed, and the erythrocytes were washed 3 times in HEPES buffered Krebs-Ringer solution, containing $125 \mathrm{mmol} / \mathrm{L}$ $\mathrm{NaCl}, 2.7 \mathrm{mmol} / \mathrm{L} \mathrm{KCl}, 1.2 \mathrm{mmol} / \mathrm{L} \mathrm{MgCl}_{2}, 1.2 \mathrm{mmol} / \mathrm{L}$ $\mathrm{KH}_{2} \mathrm{PO}_{4}$, and $5 \mathrm{mmol} / \mathrm{L}$ glucose.

The samples $(500 \mu \mathrm{L})$ of heparinised blood or erythrocytes were deproteinised with an equal volume of $1.3 \mathrm{~mol} / \mathrm{L}$ $\mathrm{HClO}_{4}$, mixed, and then centrifuged at $20,000 \times g$ for $5 \mathrm{~min}$ at $4{ }^{\circ} \mathrm{C}$. The supernatant $(400 \mu \mathrm{L})$ was neutralised with $130-160 \mu \mathrm{L}$ of $1 \mathrm{~mol} / \mathrm{L} \mathrm{K} \mathrm{K}_{3} \mathrm{PO}_{4}$ (to $\mathrm{pH} 5-7$ ). The samples were centrifuged again under the same conditions as previously, and aliquots of $100 \mu \mathrm{L}$ were injected into the sample loop. Purines were separated using a gradient elution system (buffer A: $150 \mathrm{mmol} / \mathrm{L} \mathrm{KH}_{2} \mathrm{PO}_{4} / \mathrm{K}_{2} \mathrm{HPO}_{4}, 150 \mathrm{mmol} / \mathrm{L} \mathrm{KCl}$, pH 6.0; buffer B: $15 \%$ solution of acetonitrile in buffer $\mathrm{A}$ ) at a flow rate of $1 \mathrm{~mL} / \mathrm{min}$. Peaks were detected by absorbance at
$254 \mathrm{~nm}$. Chromatographic analysis was performed using a Hewlett-Packard Series 1050/1100 chromatograph.

The concentrations of nucleotides being determined were expressed in relation to erythrocyte volume. The isolated and washed erythrocytes were collected in Modulohm glass capillaries (volume $20 \mu \mathrm{L}$, length $75 \mathrm{~mm}$ ). Hematocrit values were determined in duplicate by standard microhematocrit method and expressed as a percentage. The intra-erythrocyte concentrations of ATP, ADP, AMP and IMP are expressed as $\mu \mathrm{mol} / \mathrm{L}$ red blood cell (RBC). The concentrations of Hyp, Xan, UA and Urd, being present in both erythrocytes and plasma, are expressed as $\mu \mathrm{mol} / \mathrm{L}$ whole blood.

The values of total adenine nucleotide pool (TAN) and adenylate energy charge (AEC) were also calculated [2]:

$$
\begin{aligned}
& \mathrm{TAN}=\mathrm{ATP}+\mathrm{ADP}+\mathrm{AMP} \\
& \mathrm{AEC}=\frac{[\mathrm{ATP}]+0.5[\mathrm{ADP}]}{[\mathrm{ATP}]+[\mathrm{ADP}]+[\mathrm{AMP}]} .
\end{aligned}
$$

\section{Determination of erythrocyte APRT and HGPRT activity}

The activity of APRT and HGPRT was determined by HPLC in an erythrocyte lysate according to Sakuma et al. [26] and Rylance et al. [27].

The erythrocytes were separated by centrifugation at $1500 \times g$ for $10 \mathrm{~min}$ at $4{ }^{\circ} \mathrm{C}$, washed 3 times with $0.9 \%$ $\mathrm{NaCl}$ and frozen at $-80{ }^{\circ} \mathrm{C}$.

$100 \mu \mathrm{L}$ of lysate was diluted with $500 \mu \mathrm{L}$ of cold charcoal-dextran suspension containing $3.0 \mathrm{~g} / \mathrm{L}$ charcoal and $0.3 \mathrm{~g} / \mathrm{L}$ dextran in cold distilled water. After mixing for about $10 \mathrm{~s}$ in a vortex mixer, the lysates were left for $15 \mathrm{~min}$ at $4{ }^{\circ} \mathrm{C}$, then centrifuged at $10000 \times g$ for $15 \mathrm{~min}$ at $4{ }^{\circ} \mathrm{C}$. The supernatants were used as samples for enzyme activity determination.

In the erythrocyte lysates, hemoglobin concentrations $(\mathrm{Hb})$ was determined by the Drabkin's method.

The enzyme reactions were started by adding $25 \mu \mathrm{L}$ of erythrocyte lysate to the substrate mixture containing: $250 \mu \mathrm{L}$ reagent A $(100 \mathrm{mmol} / \mathrm{L}$ Tris $\mathrm{HCl} \mathrm{pH}$ 7.4, $12 \mathrm{mmol} / \mathrm{L} \mathrm{MgCl}_{2}, 2 \mathrm{mmol} / \mathrm{L}$ Hyp, $0.4 \mathrm{mmol} / \mathrm{L}$ adenine) and $250 \mu \mathrm{L} 2 \mathrm{mmol} / \mathrm{L}$ PRPP. After $5 \mathrm{~min}$ of incubation at $37 \mathrm{C}$, a $200-\mu \mathrm{L}$ sample was collected and placed in an Eppendorf tube containing $200 \mu \mathrm{L}$ of $1.3 \mathrm{~mol} / \mathrm{L} \mathrm{HClO}_{4}$. After further $25 \mathrm{~min}$ of incubation, another $200 \mu \mathrm{L}$ sample was collected and also placed in an Eppendorf tube containing $\mathrm{HClO}_{4}$. The samples were centrifuged $(14,000 \times g$, $\left.5 \mathrm{~min}, 4^{\circ} \mathrm{C}\right)$. The supernatant $(200 \mu \mathrm{L})$ was neutralized (pH 5-7) with $1 \mathrm{~mol} / \mathrm{L} \mathrm{K}_{3} \mathrm{PO}_{4}$. The samples were centrifuged again (under the same conditions as previously) and $100 \mu \mathrm{L}$ was taken for HPLC analysis [25]. 
The APRT activity was calculated from the increase of $\mathrm{AMP}+\mathrm{ADP}+\mathrm{ATP}$ between samples taken at 5 and $30 \mathrm{~min}$ of incubation and expressed as $\mathrm{nmol} / \mathrm{min} / \mathrm{mg} \mathrm{Hb}$.

The HPRT activity was calculated from the increase of IMP between samples taken at 5 and 30 min of incubation and expressed as nmol/min/mg $\mathrm{Hb}$.

\section{Determination of erythrocyte PRPP-S activity}

The erythrocytes were separated by centrifugation at $1500 \times g$ for $10 \mathrm{~min}$ at $4{ }^{\circ} \mathrm{C}$. The received pellet was washed twice with PBS and then frozen and thawed two times, resuspended in $1 \mathrm{~mL}$ of ice-cold deionized water and used directly for PRPP-S quantification.

Measurement of the PRPP-S activity was performed using a Precice ${ }^{\circledR}$ kit (Novocib, Lyon, France). The assay is based on a reaction in which, in the presence of ATP and P-ribose, PRPP-synthetase catalyzes the formation of PRPP. In the presence of Hyp, PRPP is converted to IMP by hypoxanthine-guanine phosphoribosyltransferase. IMP is immediately oxidized by a highly active IMP dehydrogenase in the presence of NAD with simultaneous formation of $\mathrm{NADH}_{2}$ being directly monitored spectrophotometrically at $340 \mathrm{~nm}$. Assay results are reported in nmol of IMP formed per hour and per mg of hemoglobin. Hemoglobin concentration was determined in hemolysates using the Drabkin's reagent.

\section{Determination of erythrocyte PRPP concentrations}

The erythrocytes were separated by centrifugation at $1500 \times g$ for $10 \mathrm{~min}$ at $4{ }^{\circ} \mathrm{C}$. The received pellet was washed three times with PBS and, after protein precipitation, PRPP concentrations were determined using a Precice ${ }^{\circledR}$ kit (Novocib, Lyon, France). In the presence of Hyp, HGPRT converts PRPP to IMP which is further oxidized to XMP (xanthosine 5'-monophosphate) by downstream IMP dehydrogenase enzyme leading to simultaneous $\mathrm{NADH}_{2}$ formation. The amount of $\mathrm{NADH}_{2}$ formed is measured spectrophotometrically at $340 \mathrm{~nm}$ and is equivalent to the amount of PRPP in the assay.

\section{Density separation of red blood cells}

The RBCs were separated according to their density using discontinuous iodixanol (OptiPrep ${ }^{\circledR}$, Nycomed) density gradients [28]. Five iodixanol layers (2 mL each), with densities of $1.075,1.085,1.095,1.105$ and $1.115 \mathrm{~g} / \mathrm{mL}$, were carefully layered on top of each other in a test tube, with the densest one at the bottom. One $\mathrm{ml}$ of whole blood was carefully layered on top of the least dense layer and the tube was centrifuged at $2500 \times g$ for $25 \mathrm{~min}$ at $22{ }^{\circ} \mathrm{C}$. Each layer was carefully obtained separately. The density distribution of RBCs was estimated by determining the hemoglobin concentration in each layer. Because the erythrocyte density increases as a function of age [29], old cells accumulated at the bottom (dense) layers of iodixanol.

\section{Statistical analysis}

Statistical analyses were performed using STATISTICA (data analysis software system), version 10 software (StatSoft, Inc., 2011). Distributions were examined using a Shapiro-Wilk test which showed that some variables departed from a normal distribution (they were log-normal; values were reported as median and $Q_{25}-Q_{75}$ ).

Significance level of differences observed between analyzed time points (before exercise vs. after exercise vs. 30 min after exercise) for each participant was calculated using Friedman's ANOVA with Dunn's test for post hoc analysis. The significance level of differences observed between groups (untrained vs. trained) was calculated using the Mann-Whitney U test.

The accepted level of significance was defined as $P<0.05$.

In order to demonstrate whether the observed correlations were statistically significant, Spearman's rank correlation coefficient was applied.

\section{Results}

The study enrolled 15 sedentary young men aged $23.1 \pm 3.41$ years and 15 rowers aged $24.3 \pm 2.56$ years with a BMI between $21.5 \pm 2.51 \mathrm{~kg} / \mathrm{m}^{2}$ (trained) and $22.5 \pm 2.32 \mathrm{~kg} / \mathrm{m}^{2}$ (sedentary). Immediately before the exercise test, heart rate and blood pressure measurements were performed. The values obtained were within normal ranges and did not differ significantly between the two treatment groups. In the group of sedentary subjects, the time of exercise test was $19.3 \pm 4.55 \mathrm{~min}$, whereas in that of trained subjects, $23.0 \pm 5.97 \mathrm{~min}$. In trained subjects, oxygen consumption at maximum load $(52.8 \pm 4.54 \mathrm{~mL} / \mathrm{kg} /$ min) was significantly higher $(P<0.001)$ compared with the sedentary ones $(43.2 \pm 5.20 \mathrm{~mL} / \mathrm{kg} / \mathrm{min}$; Table 1$)$.

The effect of exercise on $\mathrm{pH}$, venous blood gases, inorganic phosphorous $(\mathrm{Pi})$ and lactate concentration (LA) is presented in Table 2 .

Immediately after the physical exercise, a significant decrease was observed in $\mathrm{pH}(P<0.01)$ and $\mathrm{pCO}_{2}$ $(P<0.05)$, as well as in the concentration of $\mathrm{HCO}_{3}^{-}$ $(P<0.01)$, in both treatment groups without significant differences between them. At $30 \mathrm{~min}$ of recovery, $\mathrm{pH}$ and $\mathrm{pCO}_{2}$, as well as the concentration of $\mathrm{HCO}_{3}^{-}$, did not differ significantly from the values being observed before the exercise (Table 2). 
Table 2 The effect of exercise on venous blood gases, inorganic phosphorus and lactate concentration

\begin{tabular}{|c|c|c|c|c|c|c|}
\hline & \multicolumn{3}{|c|}{ Sedentary group } & \multicolumn{3}{|l|}{ Trained group } \\
\hline & Rest & Post-exercise & 30-min recovery & Rest & Post-exercise & 30-min recovery \\
\hline $\mathrm{pH}$ & $7.4 \pm 0.06$ & $7.2 \pm 0.05^{* *}$ & $7.4 \pm 0.04$ & $7.4 \pm 0.06$ & $7.2 \pm 0.08^{*}$ & $7.4 \pm 0.04$ \\
\hline $\mathrm{pO}_{2}(\mathrm{mmHg})$ & $31.8 \pm 8.03$ & $42.3 \pm 7.15$ & $32.5 \pm 7.03$ & $32.0 \pm 7.89$ & $44.3 \pm 7.25$ & $31.8 \pm 7.13$ \\
\hline $\mathrm{pCO}_{2}(\mathrm{mmHg})$ & $42.3 \pm 1.20$ & $35.2 \pm 1.82^{*}$ & $41.3 \pm 0.9$ & $42.8 \pm 1.19$ & $36.8 \pm 1.62 *$ & $41.4 \pm 0.89$ \\
\hline $\begin{array}{l}\mathrm{HCO}_{3}^{-} \\
(\mathrm{mmol} / \mathrm{L})\end{array}$ & $23.3 \pm 0.90$ & $18.7 \pm 1.81^{* *}$ & $22.1 \pm 1.21$ & $23.2 \pm 0.88$ & $19.6 \pm 1.61^{* *}$ & $22.8 \pm 1.11$ \\
\hline $\mathrm{Pi}$ in plasma $(\mathrm{mmol} / \mathrm{L})$ & $1.21 \pm 0.41$ & $1.42 \pm 0.78^{\#}$ & $1.41 \pm 0.64^{\#}$ & $1.14 \pm 0.39$ & $1.45 \pm 0.63^{\#}$ & $1.37 \pm 0.58^{\#}$ \\
\hline $\mathrm{Pi}$ in $\mathrm{RBC}(\mathrm{mmol} / \mathrm{L})$ & $1.11 \pm 0.21$ & $1.39 \pm 0.20^{*}$ & $1.17 \pm 0.16$ & $1.16 \pm 0.14$ & $1.32 \pm 0.22 *$ & $1.17 \pm 0.14$ \\
\hline $\mathrm{LA}(\mathrm{mmol} / \mathrm{L})$ & $1.4 \pm 0.45$ & $10.1 \pm 2.76^{* * *}$ & $4.6^{\# \#, \S} \pm 1.66$ & $1.7 \pm 0.37$ & $9.8 \pm 2.65^{* * *}$ & $3.6 \pm 1.25^{\# \# \S}$ \\
\hline
\end{tabular}

Values are given as mean $\pm \mathrm{SD}$

$\mathrm{pO}_{2}$ oxygen tension, $\mathrm{pCO}_{2}$ carbon dioxide tension, $\mathrm{HCO}_{3}^{-}$bicarbonate, $\mathrm{Pi}$ inorganic phosphorous, $\mathrm{LA}$ lactate

$* P<0.05$; ** $P<0.01$; *** $P<0.001$; different from rest and 30-min recovery

${ }^{\#} P<0.05 ;{ }^{\# \#} P<0.01 ;$ different from rest

$\S P<0.001$; different from post-exercise

Immediately after exercise, a significant $(P<0.05)$ increase, being maintained at $30 \mathrm{~min}$ of recovery, in $\mathrm{Pi}$ concentration in plasma was shown, too. The Pi concentration in RBCs was significantly higher $(P<0.05)$ after the physical exercise only (Table 2).

An approximately five-fold increase in blood LA concentration $(P<0.001)$ in both treatment groups was also demonstrated immediately after exercise without significant differences between sedentary and trained subjects. At $30 \mathrm{~min}$ of recovery, blood lactate concentration significantly decreased $(P<0.001)$ compared with the post-exercise value but was still significantly higher $(P<0.01)$ compared with the rest values (Table 2).

The study showed a significantly higher $(P<0.01)$ concentration of 2,3-BPG in RBCs in trained subjects $(2.3 \pm 0.18 \mu \mathrm{mol} / \mathrm{mL})$ than in the sedentary ones $(1.85 \pm 0.21 \mu \mathrm{mol} / \mathrm{mL}$; Table 1$)$.

The density distribution of RBCs in the sedentary and trained groups is presented in Fig. 1. In both treatment groups, most RBCs accumulated in the layers with densities between 1.096 and $1.105 \mathrm{~g} / \mathrm{mL}$. In the layer of density $1.095 \mathrm{~g} / \mathrm{mL}$ (where younger erythrocytes accumulate), sedentary and trained erythrocytes were $29.8 \pm 2.94$ and $43.9 \pm 4.66 \%$, respectively $(P<0.01)$. In the layer of density $1.105 \mathrm{~g} / \mathrm{mL}$, sedentary and trained erythrocytes were $48.0 \pm 1.59$ and $42.1 \pm 2.06 \%$, respectively $(P<0.001)$. In the layers of densities $1.075,1.085$ and $1.095 \mathrm{~g} / \mathrm{mL}$, where younger erythrocytes were accumulated, the percentage of erythrocytes from sedentary subjects was $32.2 \%$, whereas in the trained ones, it was $46.6 \%$.

The effect of physical exercise on purine nucleotide concentration in the group of sedentary and trained subjects is presented in Table 3. In the group of trained subjects, a significantly higher $(P<0.01)$ concentration of ATP was

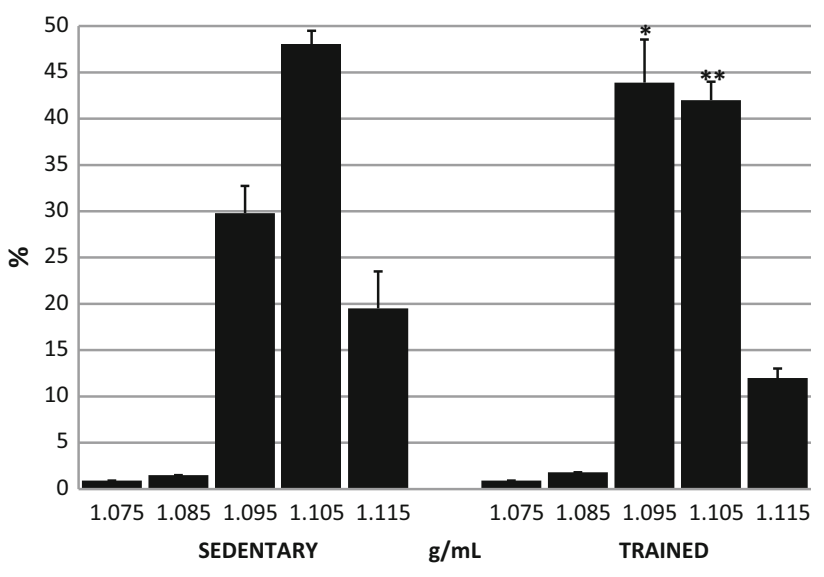

Fig. 1 Percentage of RBCs distributed in density fractions between 1.075 and $1.115 \mathrm{~g} / \mathrm{mL}$ in sedentary and trained subjects. ${ }^{*} P<0.05$; $* * P<0.01 ;$ different from sedentary

demonstrated at rest, after exercise and at 30 min of recovery compared with the sedentary group, whereas in both treatment groups, no post-exercise changes in ATP concentration were observed; the concentration of ADP and AMP significantly decreased $(P<0.01)$ at the 30th minute of recovery without significant differences between sedentary and trained subjects (Table 3). A significant decrease in ADP and AMP was accompanied by a significant increase $(P<0.01)$ in the value of AEC without changes in TAN (Table 3 ) and a significant increase in the ADP/AMP ratio (Fig. 2; $P<0.01$ ). Although erythrocyte ATP/ADP ratios significantly increased in both groups (at the 30th minute of recovery), the ATP/ADP ratio was significantly higher $(P<0.001)$ in trained subjects compared with the sedentary ones (Fig. 3). In both treatment groups, a significant (Table $3 ; P<0.01$ ) post-exercise increase in IMP concentration in RBCs was observed (Table 3). 

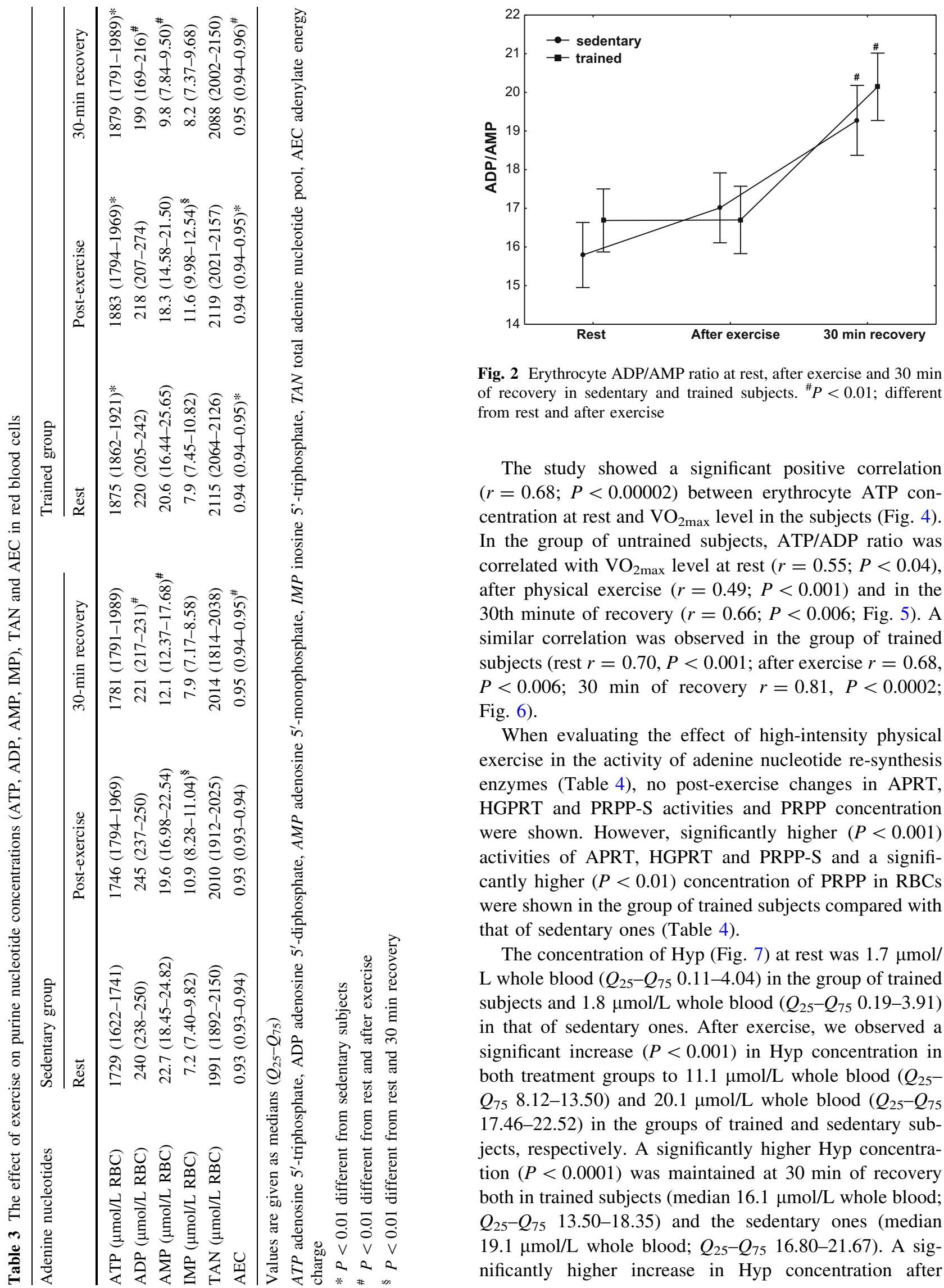

Fig. 2 Erythrocyte ADP/AMP ratio at rest, after exercise and $30 \mathrm{~min}$ of recovery in sedentary and trained subjects. ${ }^{\#} P<0.01$; different from rest and after exercise

The study showed a significant positive correlation ( $r=0.68 ; P<0.00002)$ between erythrocyte ATP concentration at rest and $\mathrm{VO}_{2 \max }$ level in the subjects (Fig. 4). In the group of untrained subjects, ATP/ADP ratio was correlated with $\mathrm{VO}_{2 \max }$ level at rest $(r=0.55 ; P<0.04)$, after physical exercise $(r=0.49 ; P<0.001)$ and in the 30th minute of recovery $(r=0.66 ; P<0.006$; Fig. 5). A similar correlation was observed in the group of trained subjects (rest $r=0.70, P<0.001$; after exercise $r=0.68$, $P<0.006 ; 30 \mathrm{~min}$ of recovery $r=0.81, P<0.0002$; Fig. 6).

When evaluating the effect of high-intensity physical exercise in the activity of adenine nucleotide re-synthesis enzymes (Table 4), no post-exercise changes in APRT, HGPRT and PRPP-S activities and PRPP concentration were shown. However, significantly higher $(P<0.001)$ activities of APRT, HGPRT and PRPP-S and a significantly higher $(P<0.01)$ concentration of PRPP in RBCs were shown in the group of trained subjects compared with that of sedentary ones (Table 4).

The concentration of Hyp (Fig. 7) at rest was $1.7 \mu \mathrm{mol} /$ $\mathrm{L}$ whole blood $\left(Q_{25}-Q_{75} 0.11-4.04\right)$ in the group of trained subjects and $1.8 \mu \mathrm{mol} / \mathrm{L}$ whole blood $\left(Q_{25}-Q_{75} 0.19-3.91\right)$ in that of sedentary ones. After exercise, we observed a significant increase $(P<0.001)$ in Hyp concentration in both treatment groups to $11.1 \mu \mathrm{mol} / \mathrm{L}$ whole blood $\left(Q_{25}\right.$ $\left.Q_{75} 8.12-13.50\right)$ and $20.1 \mu \mathrm{mol} / \mathrm{L}$ whole blood $\left(Q_{25}-Q_{75}\right.$ 17.46-22.52) in the groups of trained and sedentary subjects, respectively. A significantly higher Hyp concentration $(P<0.0001)$ was maintained at $30 \mathrm{~min}$ of recovery both in trained subjects (median $16.1 \mu \mathrm{mol} / \mathrm{L}$ whole blood; $Q_{25}-Q_{75} 13.50-18.35$ ) and the sedentary ones (median $19.1 \mu \mathrm{mol} / \mathrm{L}$ whole blood; $Q_{25}-Q_{75} 16.80-21.67$ ). A significantly higher increase in Hyp concentration after 


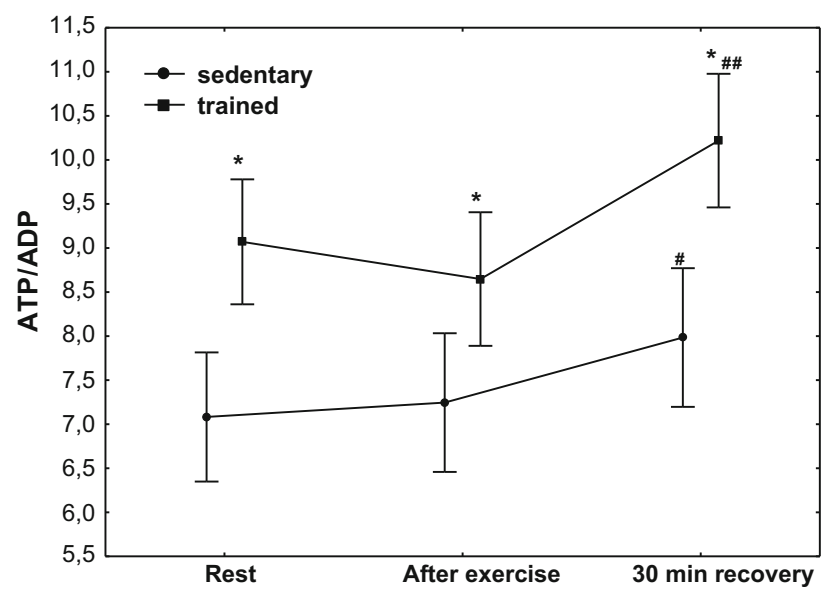

Fig. 3 Erythrocyte ATP/ADP ratio at rest, after exercise and $30 \mathrm{~min}$ of recovery in sedentary and trained subjects. ${ }^{\#} P<0.05$; ${ }^{\# \#} P<0.01$; different from rest and after exercise. $* P<0.001$; different from sedentary

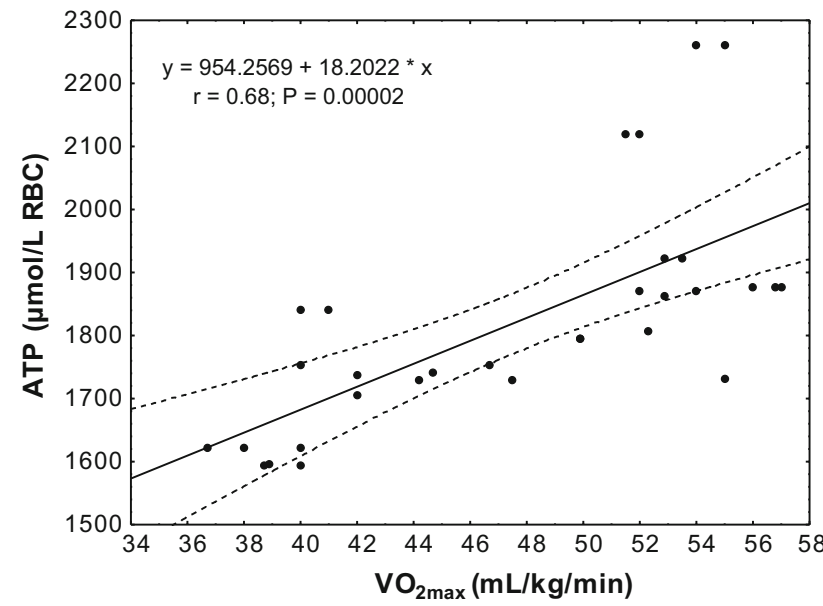

Fig. 4 Correlation between erythrocyte ATP concentration and $\mathrm{VO}_{2 \max }$ being measured at rest

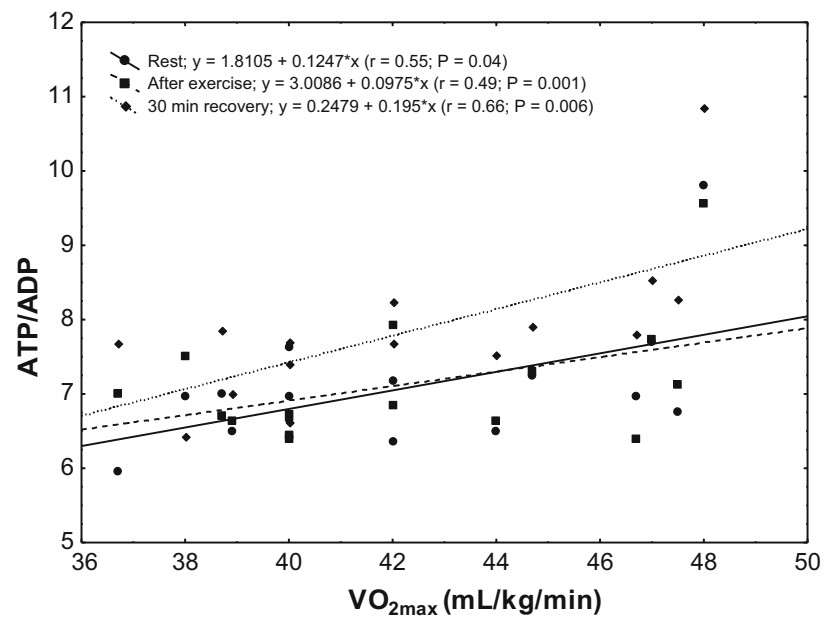

Fig. 5 Correlation between erythrocyte ATP/ADP ratio and $\mathrm{VO}_{2 \max }$ in the sedentary group

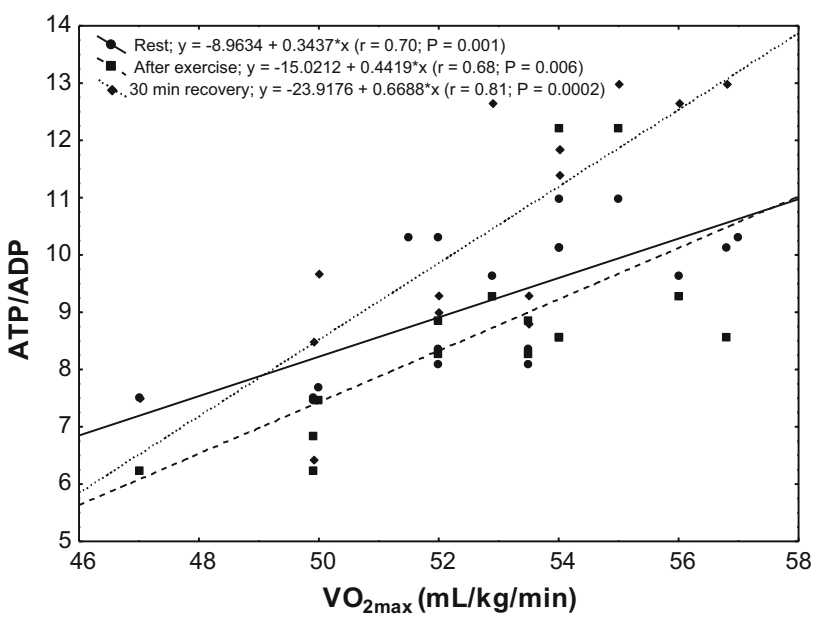

Fig. 6 Correlation between erythrocyte ATP/ADP ratio and $\mathrm{VO}_{2 \max }$ in the trained group

exercise $(P<0.0001)$ and at $30 \mathrm{~min}$ of recovery $(P<0.002)$ in the group of sedentary subjects was shown in the study (Fig. 7).

The effect of physical exercise on Xan concentration is presented in Fig. 8. Compared to the at rest values, a significant increase $(P<0.001)$ in Xan concentration was observed in sedentary subjects, from $0.21 \mu \mathrm{mol} / \mathrm{L}$ whole blood $\left(Q_{25}-Q_{75} 0.03-0.45\right)$ to $0.65 \mu \mathrm{mol} / \mathrm{L}$ whole blood $\left(Q_{25}-Q_{75} 0.40-0.91\right)$, and in trained subjects $(P<0.001)$, from $0.26 \mu \mathrm{mol} / \mathrm{L}$ whole blood $\left(Q_{25}-Q_{75} \quad 0.14-0.37\right)$ to $0.42 \mu \mathrm{mol} / \mathrm{L}$ whole blood $\left(Q_{25}-Q_{75} 0.33-0.55\right)$. Compared to the at rest values, a significantly higher $(P<0.001)$ concentration of Xan was maintained at $30 \mathrm{~min}$ of recovery in both treatment groups. A significantly higher increase in Xan concentration after exercise $(P<0.001)$ and at $30 \mathrm{~min}$ of recovery $(P<0.001)$ was observed in the group of sedentary subjects (Fig. 8).

The concentration of UA (Fig. 9) in the group of trained subjects at rest was $203 \mu \mathrm{mol} / \mathrm{L}$ whole blood $\left(Q_{25}-Q_{75}\right.$ 189-218), while in that of sedentary ones, it was $202 \mu \mathrm{mol} /$ L whole blood ( $\left.Q_{25}-Q_{75} 188-219\right)$. No significant changes in the concentration of UA were observed in both treatment groups. A significant increase in its concentration was observed at $30 \mathrm{~min}$ of recovery both in the group of trained subjects $(P<0.001$; median $248 \mu \mathrm{mol} / \mathrm{L}$ whole blood $)$ and that of sedentary ones $(P<0.0001$; median $275 \mu \mathrm{mol} / \mathrm{L}$ whole blood), with a significantly higher increase in UA concentration $(P<0.05)$ at $30 \mathrm{~min}$ of recovery being observed in the group of sedentary subjects (Fig. 9).

The effect of physical exercise on the concentration of Urd is presented in Fig. 10. Compared to the at rest values, a significant increase $(P<0.01)$ in Urd concentration was observed in sedentary subjects, from $3.2 \mu \mathrm{mol} / \mathrm{L}$ whole blood $\left(Q_{25}-Q_{75} 2.65-3.70\right)$ to $4.4 \mu \mathrm{mol} / \mathrm{L}$ whole blood $\left(Q_{25}-Q_{75} 3.85-4.88\right)$, and in trained subjects $(P<0.05)$, 
Table 4 The effect of exercise on APRT, HPRT and PRPP-S activities and PRPP concentration in RBCs

\begin{tabular}{|c|c|c|c|c|c|c|}
\hline & \multicolumn{3}{|l|}{ Sedentary group } & \multicolumn{3}{|l|}{ Trained group } \\
\hline & Rest & Post-exercise & 30-min recovery & Rest & Post-exercise & 30-min recovery \\
\hline $\begin{array}{l}\mathrm{APRT}(\mathrm{nmol} / \mathrm{mgHb} / \\
\min )\end{array}$ & $0.39(0.35-0.43)$ & $0.39(0.38-0.42)$ & $0.37(0.33-0.42)$ & $0.48(0.48-0.57)^{* *}$ & $0.44(0.42-0.49)^{* *}$ & $0.45(0.42-0.52)^{* *}$ \\
\hline $\begin{array}{l}\text { HGPRT (nmol/ } \\
\mathrm{mgHb} / \mathrm{min})\end{array}$ & $1.68(1.55-1.88)$ & $1.77(1.61-1.88)$ & $1.68(1.53-1.82)$ & $1.91(1.86-2.03)^{* *}$ & $1.84(1.85-1.93)^{* *}$ & $1.87(1.84-1.92)^{* *}$ \\
\hline $\begin{array}{l}\text { PRPP-S (nmol/ } \\
\mathrm{mgHb} / \mathrm{min})\end{array}$ & $1.23(1.19-1.25)$ & $1.23(1.20-1.24)$ & $1.19(1.17-1.22)$ & $1.32(1.29-1.35)^{* *}$ & $1.30(1.22-1.35)^{* *}$ & $1.31(1.27-1.35)^{* *}$ \\
\hline PRPP $(\mu \mathrm{mol} / \mathrm{L})$ & $5.6(4.90-5.90)$ & $5.2(5.24-6.70)$ & $4.9(4.86-5.52)$ & $7.1(6.52-7.85)^{*}$ & $7.0(5.82-7.33) *$ & $7.1(6.91-7.4)^{*}$ \\
\hline
\end{tabular}

Values are given as median $\left(Q_{25}-Q_{75}\right)$

$A P R T$ adenine phosphoribosyltransferase (EC 2.4.2.7), HGPRT hypoxanthine-guanine phosphoribosyltransferase (HGPRT; EC 2.4.2.8), PRPP-S 5-phosphoribosyl-1-pyrophosphate synthetase (EC 2.7.6.1), PRPP 5-phosphoribosyl-1-pyrophosphate

$* P<0.01$; ** $P<0.001$; different from sedentary subjects

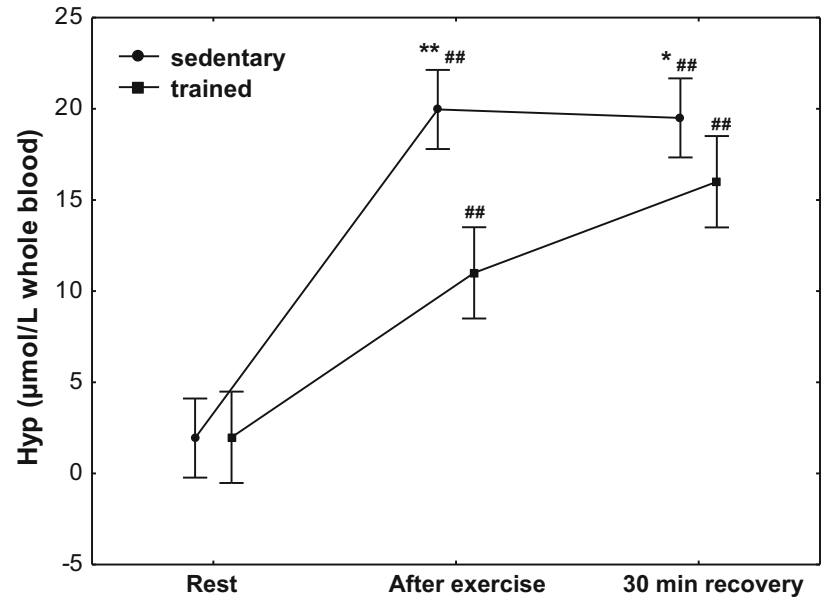

Fig. 7 Blood hypoxanthine (Hyp) concentration at rest, after exercise and $30 \mathrm{~min}$ of recovery in sedentary and trained subjects. $* P<0.002$; ${ }_{* *} P<0.0001$; different from trained. ${ }^{\# \#} P<0.001$; different from at rest

from $3.1 \mu \mathrm{mol} / \mathrm{L}$ whole blood $\left(Q_{25}-Q_{75} 2.64-3.68\right)$ to $3.7 \mu \mathrm{mol} / \mathrm{L}$ whole blood $\left(Q_{25}-Q_{75} 3.38-4.38\right)$. Sedentary subjects had significantly higher post-exercise Urd concentration compared with the trained ones $(P<0.05)$. Compared to the at rest value, a significantly higher $(P<0.05)$ concentration of Urd was maintained at $30 \mathrm{~min}$ of recovery in both treatment groups, without significant differences between them (Fig. 10).

\section{Discussion}

The study showed a significantly higher concentration of ATP in the erythrocytes of trained subjects which may at least partially reflect the increased re-synthesis of this nucleotide on the PRPP- and APRT-dependent pathway.

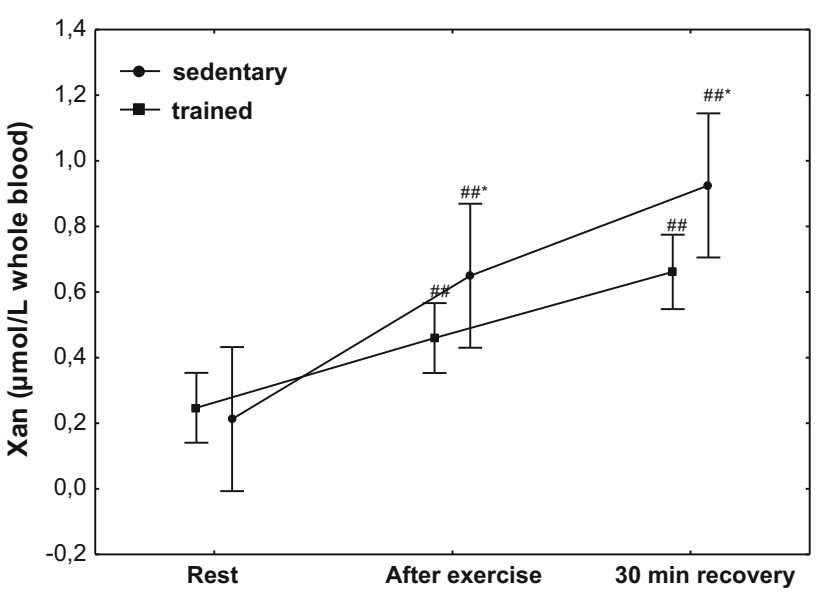

Fig. 8 Blood xanthine (Xan) concentration at rest, after exercise and $30 \mathrm{~min}$ of recovery in sedentary and trained subjects. $* P<0.001$; different from trained. ${ }^{\# \#} P<0.001$; different from at rest

This is supported by significantly higher PRPP concentration and APRT and PRPP-S activities in the erythrocytes of trained subjects. A relationship between PRPP synthesis rate and purine nucleotide biosynthesis rate regulation has been demonstrated previously [11, 30, 31]. It has been observed that APRT activity increases together with an increase in PRPP concentration [32, 33]. In human erythrocytes, PRPP concentration fluctuates around 1-5 $\mu \mathrm{mol} /$ $\mathrm{L}$ [11], just below the $\mathrm{Km}$ values of APRT and HGPRT (5-36 $\mu \mathrm{mol} / \mathrm{L})$ [31]. It is, therefore, possible that elevated levels of erythrocyte PRPP with increased PRPP-S and APRT activities would result in a higher synthetic rate of the purine salvage pathway, and could also explain the described high levels of ATP in the erythrocytes of trained subjects.

Our study also indicates that the differences being demonstrated in the concentration of analysed adenylates, 


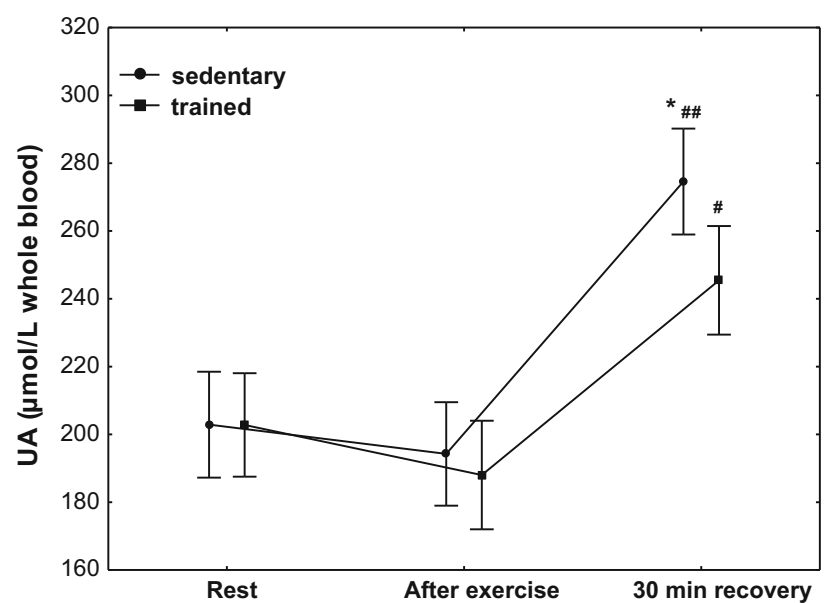

Fig. 9 Blood uric acid (UA) concentration at rest, after exercise and $30 \mathrm{~min}$ of recovery in sedentary and trained subjects. $* P<0.05$; different from trained. ${ }^{\#} P<0.001 ;{ }^{\# \#} P<0.0001$; different from rest and after exercise

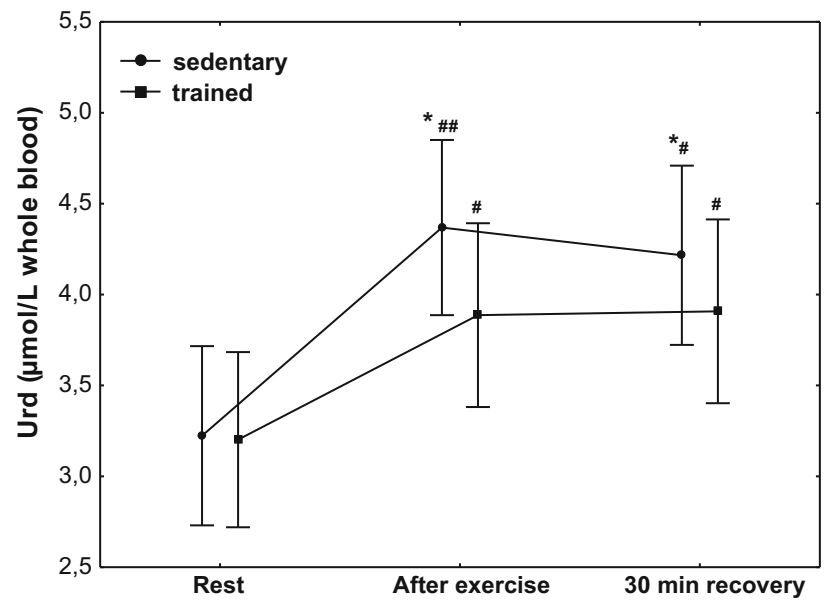

Fig. 10 Blood uridine (Urd) concentration at rest, after exercise and 30 min of recovery in sedentary and trained subjects. ${ }^{*} P<0.05$; different from trained. ${ }^{\#} P<0.05$; ${ }^{\# \#} P<0.01$; different from rest

as well as in the activity of analysed enzymes, may be in part related to the age of RBCs. In the study, RBCs were separated by density gradient centrifugation to evaluate the age distribution of erythrocytes. In comparison with the results of other authors $[29,34,35]$, our study shows an increase in the proportion of young erythrocytes in the RBC population of trained subjects. Higher APRT activity has been observed in the erythrocytes of normal newborn infants $[32,33]$ which, as shown, may result in increased adenine nucleotide concentration in the RBCs of newborn infants. Similar differences have been shown between young and old erythrocytes being fractionated from the blood of adults. It is, therefore, possible that higher erythrocyte ATP concentration in athletes may be partially explained by an increase in the proportion of young erythrocytes. Young RBCs have an increased metabolic activity [36], higher 2,3-BPG and a lower $\mathrm{Hb}-\mathrm{O}_{2}$ affinity than senescent RBCs $[37,38]$. Our study demonstrated a significantly higher concentration of ATP in the erythrocytes of trained subjects and also, for the first time, a positive correlation between ATP concentration and physical capacity, being evaluated by a direct measurement of maximal oxygen uptake $\left(\mathrm{VO}_{2 \max }\right)$. This allows us to state that erythrocyte ATP concentration is an important factor characterising physical capacity and exercise tolerance in healthy men. The presented study only allows us to speculate about the mechanisms through which ATP regulates physical capacity and $\mathrm{VO}_{2 \max }$. It is generally accepted that $\mathrm{VO}_{2 \max }$ during whole-body exercise is not constrained by mitochondrial oxygen consumption capacity but by the magnitude of oxygen delivery to the working muscles [21, 39]. Therefore, any factor(s) that improves oxygen delivery to the working muscles during physical exercise can contribute to the increased $\mathrm{VO}_{2 \max }$ and physical capacity. Recent studies have shown that erythrocyte ATP concentration is a major modulator of $\mathrm{Hb}$ affinity for oxygen. A rise in ATP leads to increased $\mathrm{Hb}-\mathrm{A}$ p50 values, resulting, in turn, in reduced erythrocyte affinity for oxygen. A linear correlation between increasing ATP concentration and increases in p50 values of $\mathrm{Hb}-\mathrm{A}$ has been observed [23]. It is, therefore, possible that better tissue oxygenation occurs together with an increase in ATP concentration in RBCs and a decrease in $\mathrm{Hb}$ affinity for oxygen and the same increases physical capacity and exercise tolerance. Thus, a significantly higher concentration of ATP in the erythrocytes of trained subjects may be an expression of favourable changes ensuring the adaptation of erythrocyte metabolism to increasing oxygen requirements of the body during physical exercise and training.

No significant post-exercise changes in ATP concentrations were observed in our study, whereas AMP and ADP concentrations in the 30th minute of recovery were significantly lower in the two groups of subjects, but differences between these groups showed no statistical significance. At the same time, a significant increase in the ATP/ADP and ADP/AMP ratios was also observed. The presented study thus suggests a post-exercise increase in the metabolism rate of ADP to ATP (significant increase in the ATP/ADP ratio). Although the physiological and clinical importance of the changes being observed is not clear, it is interesting that the erythrocyte ATP/ADP ratio shows a positive relationship with plasma nitric oxide (NO) concentration in healthy subjects (young and middle age), athlete subjects and diabetic patients [40]. It is, therefore, possible, and it will require further studies, that a postexercise increase in the ATP/ADP ratio in RBCs contributes to the control of $\mathrm{NO}$ production and the regulation 
of blood flow. It has been shown in the in vitro studies that ATP is released from human RBCs and myocardium in response to short hypoxia periods [41]. The concentration of ATP has been shown to increase in response to incremental exercise in the coronary circulation of dogs exercising on a treadmill [42] and in the femoral vein in humans during knee extensor exercise [43, 44]. ATP being released from erythrocytes into the circulation can activate purinergic receptors, specifically those of the $\mathrm{P}_{2 \mathrm{Y}}$ subfamily, present on the vascular endothelium, resulting in the synthesis and release of NO [45, 46]. NO released abluminally interacts with the vascular smooth muscle, resulting in its relaxation and increased blood flow to hypoxic/exercising tissue $[45,47]$. An original discovery of this study also is that the erythrocyte ATP/ADP ratio, as well as its exercise-induced increase, shows a significant positive correlation with $\mathrm{VO}_{2 \max }$, in both the trained and the untrained group. The correlation being demonstrated allows us to state that the erythrocyte ATP/ADP ratio, just as ATP, is one of many factors characterising exercise tolerance.

The increased $\mathrm{Pi}$ concentration in blood serum and RBCs being observed in our study after physical exercise could play a supportive role in the activation of PRPP-S because this enzyme has an absolute requirement for Pi for its activation [10, 11]. However, our study did not show any post-exercise changes in PRPP-S activity and PRPP concentration, or any changes in APRT and HGPRT activities. Similarly, Yamamoto et al. [12] have observed no changes in PRPP-S activity after moderate-intensity exercise in the athletes playing rugby football, when $\mathrm{Pi}$ concentration in blood plasma significantly increased from $1.12 \pm 0.12$ to $1.46 \pm 0.22 \mathrm{mmol} / \mathrm{L}$ and in $\mathrm{RBCs}$ from $1.06 \pm 0.10$ to $1.33 \pm 0.21 \mathrm{mmol} / \mathrm{L}$. On the basis of the data presented above, one may speculate that if Pi indeed plays an important role in erythrocyte PRPP-S activity as reported by Berman [10] and Berman and Human [11], then the magnitude of exercise-induced changes in the blood Pi being observed in our study was too small or the duration of erythrocyte exposure to high plasma Pi was too short to cause a significant increase in PRPP-S activity.

An increase in IMP concentration in RBCs after highintensity exercise has been already observed in our previous study in the group of young untrained men [18]. The present study confirms our previous results and, in addition, allows us to state that maximal physical exercise also results in an increase in IMP concentration in RBCs in the trained subjects. Because one of the routes of Hyp utilisation is its uptake by RBCs [48], a significant increase in blood Hyp concentration, as well as a significant increase in erythrocyte IMP concentration with no changes in ATP, ADP and AMP concentrations at the same time, being observed directly after physical exercise suggests that Hyp was included in the IMP pool in the reaction catalysed by HGPRT in the presence of PRPP. However, our study did not show any post-exercise changes in HGPRT and PRPP$\mathrm{S}$ activities, indicating that Hyp utilisation by IMP in RBCs after physical exercise takes place with no changes in the activity of analysed enzymes. The in vitro studies have shown that incubation of RBCs in solutions with 7.35 and $7.25 \mathrm{pH}$ and containing $\mathrm{Pi}$ at a $2-\mathrm{mmol} / \mathrm{L}$ concentration results in an increase in IMP concentration, whereas incubation in a solution with high Hyp level $(50 \mu \mathrm{mol} / \mathrm{L})$ without any changes in $\mathrm{Pi}$ concentration and $\mathrm{pH}$ induce no changes in IMP concentration [12]. In our study, an increase in IMP concentration was observed under increased Hyp concentration in blood and Pi concentration in plasma and erythrocytes. At the same time, a decrease in blood $\mathrm{pH}$ was also observed. These results suggest that an increase in IMP concentration in erythrocytes after maximal physical exercise is stimulated by a post-exercise increase in $\mathrm{Pi}$ concentration in erythrocytes. In the 30th minute of recovery, despite the persisting high concentration of Hyp in blood, an increase in IMP concentration was recorded no longer. At the same time, no changes in erythrocyte Pi concentration were observed. Thus, a decrease in $\mathrm{pH}$ and an increase in $\mathrm{Pi}$ and Hyp concentrations in blood being observed suggest that Hyp was included in the IMP pool in the reaction catalysed by HGPRT but without any changes in the post-exercise activity of this enzyme. An increase in IMP concentration in RBCs with no changes in erythrocyte HGPRT and PRPP-S activities was also observed after moderate-intensity exercise $\left(\begin{array}{lll}65 \% & \mathrm{VO}_{2 \max }\end{array}\right)$ [12].

A post-exercise increase in Hyp, Xan and UA concentrations in blood has been already observed by many authors [6, 20, 49, 50]. Numerous studies have also documented that repeated high-intensity training decreases purine nucleotide losses and reduces the post-exercise flux of purines from muscles to blood [4, 20, 51, 52]. The results of our study are thus consistent with the literature data and confirm a significantly lower postexercise increase in Hyp, Xan and UA concentrations in blood being observed in athletes. Increased ATP degradation, which accompanies high-intensity exercises, and a decrease in its concentration contribute not only to an increase in the concentration of purine degradation products (Hyp, Xan, UA) but also to reduced phosphorylation of UDP to UTP, leading to increased UDP and UMP levels. These changes accelerate pyrimidine degradation (UTP $\rightarrow$ UDP $\rightarrow$ UMP $\rightarrow$ Urd), which may result in an increase in the concentration of Urd in blood [53, 54]. Our previous studies have shown that highintensity physical exercise leads to a post-exercise, and persisting in the 30th minute of recovery, increase in Urd concentration in blood $[54,55]$. These studies have also 
shown that a post-exercise increase in Hyp concentration (myogenic purine degradation indicator) correlates with a post-exercise increase in Urd concentration in blood (myogenic pyrimidine degradation indicator) suggesting that the blood Urd level is related to skeletal muscle purine metabolism [54]. Although the results of the present study confirm our previous observations on a post-exercise increase in Urd concentration in blood $[54,55]$, they allow us, however, to state for the first time that there is a significantly lower post-exercise increase in Urd concentration in the trained subjects. Such an adaptation may have important consequences for the athletes performing high-intensity workouts as it is associated with reduction in the net losses of pyrimidine nucleotides, the participation of which in RNA synthesis, bio-membranes (via the formation of pyrimidine-lipid conjugates) and glutathione (via the formation of pyrimidine-sugar conjugates) is well-known and documented [56, 57].

Conclusion. Training results in favourable changes in purine and pyrimidine metabolism. These changes are expressed in a significantly higher concentration of ATP in the erythrocytes of trained subject, which may be partially explained by higher metabolic activity in the purine resynthesis pathway, being typical for young RBCs. The ATP concentration, just as the ATP/ADP ratio, as well as an exercise-induced increase in this ratio, correlates with the $\mathrm{VO}_{2 \max }$ level in these subjects, allowing them to be considered as the important factors characterising physical capacity and exercise tolerance. Maximal physical exercise in the group of trained subjects results not only in a lower post-exercise increase in the concentration of Hyp, Xan and UA but also in that of Urd. This indicates the possibility of performing high-intensity work with a lower loss of not only purine but also pyrimidine. A single physical exercise event results in an increase in IMP concentration in RBCs without any changes in the post-exercise activity of HGPRT, PRPP-S and PRPP.

Acknowledgements This study was supported by grant NN 404 281337 from the Ministry of Science and Higher Education, Poland. We would like to thank all those who participated in the study, as well as Mr. PhD. Przemysław Smietana from the Department of Biology at the University of Szczecin for consultation on the statistical analysis.

Authors' contributions Study concept and design: WD, AL; Conducted experiments WD; Data analysis: WD, AL; Contributed reagents/materials/analysis tools: WD, AL; Biochemical analysis: WD, KJ, MO; Statistical analysis: WD, KS, DCH; Wrote the paper: WD, MS, AL, DCH; Collection of funds: WD, AL.

\section{Compliance with ethical standards}

Conflict of interest The authors declare that there is no conflict of interest that could be perceived as prejudicing the impartiality of the research reported.
Open Access This article is distributed under the terms of the Creative Commons Attribution 4.0 International License (http://creative commons.org/licenses/by/4.0/), which permits unrestricted use, distribution, and reproduction in any medium, provided you give appropriate credit to the original author(s) and the source, provide a link to the Creative Commons license, and indicate if changes were made.

\section{References}

1. Ataullakhanov FI, Vitvitsky VM (2002) What determines the intracellular ATP concentration. Biosci Rep 22(5):501-511

2. Dudzinska W, Hlynczak AJ, Skotnicka E, Suska M (2006) The purine metabolism of human erythrocytes. Biochemistry (Mosc) $71: 467-475$

3. Saugstag OD (1988) Hypoxanthine as in indicator of hypoxia: its role in health and disease through free radical production. Pediatr Res 23(2):143-150

4. Stathis CG, Febbraio MA, Carey MF, Snow RJ (1994) Influence of sprint training on human skeletal muscle purine nucleotide metabolism. J Appl Physiol 76:1802-1809

5. Hellsten Y, Richter EA, Kiens B, Bangsbo J (1999) AMP deamination and purine exchange in human skeletal muscle during and after intense exercise. J Physiol 520:909-920

6. Bangsbo J, Sjödin B, Hellsten-Westing Y (1992) Exchange of hypoxanthine in muscle during intense exercise in man. Acta Physiol Scand 146:528-533

7. Hellsten-Westing Y, Ekblom B, Kajser I, Sjödin B (1994) Exchange of purines in human liver and skeletal muscle with short-term exhaustive exercise. Am J Physiol 266:81-86

8. Stathis CG, Zhao S, Carey MF, Snow RJ (1999) Purine loss after repeated sprint bouts in humans. J Appl Physiol 87(6):2037-2042

9. Zhao S, Snow RJ, Stathis G, Febbraio MA, Carey MF (2000) Muscle adenine nucleotide metabolism during and recovery from maximal exercise in humans. J Appl Physiol 88:1513-1519

10. Berman PA, Black DA, Human L, Harley EH (1988) Oxypurine cycle in human erythrocytes regulated by $\mathrm{pH}$, inorganic phosphate, and oxygen. J Clin Invest 82:980-986

11. Berman PA, Human L (1990) Regulation of 5-phosphoribosyl 1-pyrophosphate and of hypoxanthine uptake and release in human erythrocytes by oxypurine cycling. J Biol Chem 265:6562-6568

12. Yamamoto T, Moriwaki Y, Takahashi S, Ishizashi H, Higashino K (1994) Effect of muscular exercise by bicycle ergometer on erythrocyte purine nucleotides. Horm Metab Res 26:504-508

13. Lichman M, Miller DR (1970) Erythrocyte glycolysis, 2,3diphosphoglycerate and adenosine triphosphate concentration in uremic subjects: relationship to extracellular phosphate concentration. J Lab Clin Med 76:267-278

14. Mansell MA, Allsop J, North ME, Simmonds RJ, Harkness RA, Watts RW (1981) Effect of renal failure on erythrocyte purine nucleotide, nucleoside and base concentrations and some related enzyme activities. Clin. Sci (London) 61(6):757-764

15. Marlewski M, Smolenski RT, Szolkiewicz M, Aleksandrowicz Z, Rutkowski B (2000) Increased rate of adenine incorporation into adenine nucleotide pool in erythrocytes of patients with chronic renal failure. Nephron 86:281-286

16. Skotnicka E, Baranowska-Bosiacka I, Dudzińska W, Suska M, Nowak R (2008) The effect of exhaustive exercise on the concentration of purine nucleotides and their metabolites in erythrocytes. Biol Sport 25(1):35-55

17. Wagner DR, Felbel J, Gresser J, Zollner N (1991) Muscle metabolism and red cell ATP/ADP concentration during bicycle ergometer in patients with AMPD-deficiency. Klin Wochenschr 69:251-255 
18. Dudzinska W, Lubkowska A, Dolegowska B, Safranow K, Jakubowska K (2010) Adenine, guanine and pyridine nucleotides in blood during physical exercise and restitution in healthy subjects. Eur J Appl Physiol 110(6):1155-1162

19. Mairbäurl H (2013) Red blood cells in sports: effects of exercise and training on oxygen supply by red blood cells. Front Physiol 4:332-345

20. Hellsten-Westing Y, Balsom PD, Norman B, Sjödin B (1993) The effect of high-intensity training on purine metabolism in man. Acta Physiol Scand 149:405-412

21. Bassett DR, Howley ET (2000) Limiting factors for maximum oxygen uptake and determinants of endurance performance. Med Sci in Sport Exer 32(1):70-84

22. Zoladz JA, Majerczak J, Duda K, Chłopicki S (2009) Exerciseinduced prostacyclin release positively correlates with $\mathrm{VO}_{2 \max }$ in young healthy men. Physiol Res 58:229-238

23. O'Brien WG III, Berka V, Tsai AL, Zhao Z, Lee CC (2015) CD73 and AMPD3 deficiency enhance metabolic performance via erythrocyte ATP that decreases hemoglobin oxygen affinity. Sci Rep 5:131-147

24. Ziemann E, Olek RA, Grzywacz T, Antosiewicz J, Kujach S, Luszczyk M, Smaruj M, Sledziewska E, Laskowski R (2013) Whole-body cryostimulation as an effective method of reducing low-grade inflammation in obese men. J Physiol Sci 63:333-343

25. Smolenski RT, Lachno DR, Ledingham SJM, Yacoub MH (1990) Determination of sixteen nucleotides, nucleosides and bases using high-performance liquid chromatography and its application to the study of purine metabolism in heart for transplantation. J Chromatogr 527:414-420

26. Sakuma R, Nishina T, Kitamura M, Yamanaka H, Kamatani N (1987) Screening for adenine and hypoxanthine phosphoribosyltransferase deficiencies in human erythrocytes by high-performance liquid chromatography. Clin Chim Acta 170:281-289

27. Rylance HJ, Wallace RC, Nuki G (1982) Hypoxanthine-guanine phosphoribosyl transferase: assay using high performance liquid chromatography. Clin Chim Acta 121:159-165

28. Tugral EO, Yalcin O, Baskurt K (2002) Effect of donor age on the deformability and aggregability of density-separated red blood cells. Turk J Hematol 19:303-308

29. Sentürk UK, Gündüz F, Kuru O, Koçer G, Ozkaya YG (2005) Exercise-induced oxidative stress leads hemolysis in sedentary but not trained humans. J Appl Physiol 99(4):1434-1441

30. Becker MA (1976) Patterns of phosphoribosylpyrophosphate and ribose-5-phosphate concentration and generation in fibroblasts from patients with gout and purine overproduction. J Clin Invest 57(2):308-318

31. Becher HJ, Weise U, Volkermann G, Schollmeyer P (1980) Enhanced purine nucleotide synthesis in erythrocytes of uremic patients. Klin Wochenschr 58:1243-1250

32. Borden M, Nyhan WL, Bakay B (1974) Increased activity of adenine phosphoribosylransferase in erythrocytes of normal newborn infants. Pediat Res 8:31-36

33. Müller MM, Wagenbichler P (1977) Activity of the salvagepathway in erythrocytes of newborn infants, children and adults. Purine Metabolism in Man-II. Adv Exp Med Biol 76A:129-138

34. Weight LM, Byrne MJ, Jacobs P (1991) Haemolytic effects of exercise. Clin Sci (Lond) 81:147-152

35. Smith JA (1995) Exercise, training and red blood cell turnover. Sports Med 19:9-31

36. Seaman C, Wyss S, Piomelli S (1980) The decline in energetic metabolism with aging of the erythrocyte and its relationship to cell death. Am J Hematol 8(1):31-42

37. Haidas S, Labie D, Kaplan JC (1971) 2,3-Diphosphoglycerate content and oxygen affinity as a function of red cell age in normal individuals. Blood 38(4):463-467
38. Mairbäurl H, Humpeler E, Schwaberger G, Pessenhofer H (1983) Training dependent changes of red cell density and erythrocytic oxygen transport. J Appl Physiol 55(5):1403-1407

39. Saltin B, Calbet JA (2006) Point: in health and in a normoxic environment, $\mathrm{VO}_{2 \max }$ is limited primarily by cardiac output and locomotor muscle blood flow. J Appl Physiol 100:744-745

40. Bakhtiari N, Hosseinkhani S, Larijani B, Mohajeri-Tehrani MR, Fallah A (2012) Red blood cell ATP/ADP \& nitric oxide: the best vasodilators in diabetic patients. J Diabetes Met Dis 11:9-12

41. Bergfeld GR, Forrester T (1992) Release of ATP from human erythrocytes in response to a brief period of hypoxia and hypercapnia. Cardiovasc Res 26:40-47

42. Farias M, Gorman MW, Savage MV, Feigl EO (2005) Plasma ATP during exercise: possible role in regulation of coronary blood flow. Am J Physiol Heart Circ Physiol 288(4):1586-1590

43. Yegutkin GG, Samburski SS, Mortensen SP, Jalkanen S, Gonzalez-Alonso J (2007) Intravascular ADP and soluble nucleotidases contribute to acute prothrombotic state during vigorous exercise in humans. J Physiol 579:553-564

44. Gonzalez-Alonso J, Olsen DB, Saltin B (2009) Erythrocyte and the regulation of human skeletal muscle blood flow and oxygen delivery: role of circulating ATP. Circ Res 91:1046-1055

45. Ellsworth ML, Forrester T, Ellis CG, Dietrich HH (1995) The erythrocyte as a regulator of vascular tone. Am J Physiol 269:155-161

46. Sprague RS, Ellsworth ML, Stephenson AH, Lonigro AJ (1996) ATP: the red blood cell link to NO and local control of the pulmonary circulation. Am J Physiol 271:2717-2722

47. Jensen FB (2009) The dual roles of red blood cel in tissue oxygen delivery: oxygen carriers and regulators of local blood flow. J Exp Biol 212:3387-3393

48. Giacomello A, Salerno C (1979) Hypoxanthine uptake by human erythrocytes. FEBS Lett 107(1):203-204

49. Hellsten-Westing Y, Sollevi A, Sjödin B (1991) Plasma accumulation of hypoxanthine, uric acid and creatine kinase following exhausting runs of differing durations in man. Eur J Appl Physiol Occup Physiol 62(5):380-384

50. Sahlin K, Ekberg K, Cizinsky S (1991) Changes in plasma hypoxanthine and free radical markers during exercise in man. Acta Physiol Scand 142:275-281

51. Stathis CG, Carey MF, Hayes A, Garnham AP, Snow RJ (2006) Sprint training reduces urinary purine loss following intense exercise in humans. App Physiol Nutr Metab 31:702-708

52. Spencer M, Bishop D, Lawrence S (2004) Longitudinal assessment of the effects of field hockey training on repeated sprint ability. J Sci Med Sport 7:323-334

53. Yamamoto T, Moriwaki Y, Takahashi S, Tsutsumi Z, Yamakita J (1997) Effect of muscular exercise on the concentration of uridine and purine bases in plasma-adenosine triphosphate consumptioninduced pyrimidine degradation. Metabolism 46:1339-1342

54. Dudzinska W, Lubkowska A, Dolegowska B, Safranow K (2010) Blood uridine concentration may be an indicator of the degradation of pyrimidine nucleotides during physical exercise with increasing intensity. J Physiol Biochem 66(3):189-196

55. Dudzinska W, Lubkowska A, Jakubowska K, Suska M, Skotnicka E (2013) Insulin resistance induced by maximal exercise correlates with a post-exercise increase in uridine concentration in the blood of healthy young men. Physiol Res 62(2):163-170

56. Connolly GP, Duley JA (1999) Uridine and its nucleotides: biological actions, therapeutic potentials. Trends Pharmacol Sci 20(5):218-225

57. Löffler M, Fairbanks LD, Zameitat E, Marinaki AM, Simmonds HA (2005) Pyrimidine pathways in health and disease. Trends Mol Med 11(9):430-437 